Gazi University
Journal of Science
$\mathrm{http}: / /$ dergipark.gov.tr/gujs

\title{
An Analytical Approach for Job Evaluation
}

\author{
Mehmet Burak SENOL ${ }^{1, *(1)}$, Metin DAGDEVIREN ${ }^{1}$ (it) \\ ${ }^{I}$ Gazi University, Industrial Engineering, Ankara, Turkey

\begin{abstract}
Highlights
- Job evaluation should be considered as a multi attribute decision-making problem.

- A Fuzzy Analytical Hierarchy Process is proposed to prevent pay inequity in job evaluations.

- The vagueness and subjectivity of managers are handled with triangular fuzzy numbers.

- The most important job evaluation factors are education, product responsibility \& work environment.

- Fuzzy Analytical Hierarchy Process provides satisfactory results for a reliable payment system.
\end{abstract}

\section{Article Info}

Received: $13 / 12 / 2018$

Accepted: $22 / 05 / 2019$

Keywords
Job Evaluation
Salary
Pay Inequity
Fuzzy AHP
Multi-Criteria Decision Making

\begin{abstract}
Subjectivity within most job evaluation techniques brings about challenges and pay inequity; therefore analytical decision making tools should be applied for ranking professions. This problem should be considered as a multi attribute decision-making problem. A Fuzzy Analytical Hierarchy Process is proposed to prevent inequity problem and analytically support managers in job evaluations in this research. As a case study professions from metal industry are evaluated with respect to three factors consisting of eleven sub-factors. The AHP is used to determine job evaluation criteria weights. The vagueness and subjectivity of managers are taken into account by linguistic parameters of triangular fuzzy numbers. The most important three sub-factors are identified as education, product responsibility and work environment. Five different salary groups are determined depending on analysis. Numerical analysis reveals the advantages of F-AHP in differentiating various jobs, where F-AHP provides satisfactory results for a reliable payment system.
\end{abstract}

\section{INTRODUCTION}

The Human Resources Management (HRM) includes establishing a pay system and managing personnel contracts and agreements related to jobs. Profession Evaluation is an important duty of HRM that enable the design, establishment and improvement of human resources [1]. It is used to produce a hierarchy of jobs by measuring relative value of jobs as the basis for determining pay levels [2]. However, in an organization different kinds of jobs exist and differ in their specifications and contributions to a company, so the importance of each occupation differs from each other. This study provides an acceptable rationale for Job Evaluation in determining pay levels.

Job Evaluation studies began in the USA's public sector then widened to include private sector in 1871 . The classical four evaluation methods were developed prior to 1930s. The favorable Point Method was used by Merill R.Lott for the first time in 1924 and the Factor Comparison Method was applied by Eugene Benge in 1926, while the two other methods were developed and used earlier. These methods are still utilized in different areas of the industry. The methods applied in evaluation are ranking, classification, factor evaluation, job components and point technique [3]. The well-known and maybe the most reliable method is point method, which is widely employed in different sectors since it gets more accurate results. Professions are evaluated on a set of criteria which are ability, responsibility, effort, job conditions, etc. Points or scores are assigned according to the scale of each factors defined by levels and then total scores are calculated for jobs [4]. However point method sometimes does not provide satisfactory results to 
establish equality in pay structure systems. The seniority, success, etc. could be included to designate a reliable payment system.

Job evaluation has been employed to verify comparative significance of jobs since 1900s. However, function and importance of the evaluation in payment management system has grown as more business tried to apply similar value strategies to maintain pay equity [5]. Some researchers have considered pay inequity as the most important job evaluation term, i.e., equal pay for equal work [6,7]. Effects of job description on managers' judgments were criticized by Smith et al. (1990), while Weiner (1991) and Tiffany and (1993) examined pay inequity for same jobs for male and female, as well as for different jobs [8-10]. Ruth and Doverspike (1999) investigated effects of salary and organizational level on partiality, Mahmood et al. (1995) developed an expert system for job evaluation [6, 11]. A multi-criteria job evaluation approach considering large organizations was offered by Spyridakos et al. (2001) proposed, and Das and Garcia-Diaz (2001) computerized a statistical procedure in factor selection for job evaluation $[1,5]$. Gupta and Ahmed (1988) and Dağdeviren and Kurt (2004) employed goal programming in determining factors $[12,13]$.

Job evaluation depends on multiple factors that affect evaluation process and results. The evaluation factors are the subjective decisions of evaluation group or top managers. Fuzziness of the data related to job responsibilities and requirements bring about conflicts during the determination of job importance in large organizations [1]. The evaluation process may be considered as an administrative Multi Criteria DecisionMaking (MCDM) problem [14]. Scoring factors is a difficult task for Decision Makers (DMs) and many different scores could appear in a group of managers. Scoring factors is a fuzzy process in nature, so more accurate results could be obtained by F-AHP via reflecting various views of managers to evaluation. In addition, any partiality or the subjectivity of the DMs could be prevented. A robust MCDM method; Fuzzy Analytical Hierarchy Process (F-AHP) was employed for job evaluation [15]. Fuzzy pairwise comparisons were made so that more accurate results could have been obtained in factor selection and scoring.

We offer a Fuzzy Analytical Hierarchy Process (F-AHP) for job evaluation. This paper is made up of five sections and the rest of the paper is organized as follows. Literature review, purpose and originality of the study are explained in Section-1. This paper is one of a kind, because it employs F-AHP for job evaluation to prevent inequity problem and support managers in decision making. Numerical analysis reveals the advantages of F-AHP in differentiating various jobs. F-AHP provides satisfactory results for a reliable payment system. Section 2 was devoted to Fuzzy Analytic Hierarchy Process. Fuzzy Set Theory and Extent analysis technique were briefly explained in Section 2. Methodology of the research is presented in Section3. Here F-AHP was employed for job evaluation. Professions in a metal factory were evaluated as a case study with respect to three factors consisting of eleven sub-factors by F-AHP and results are presented in Section-4. The vagueness and subjectivity of managers are handled with linguistic parameters of triangular fuzzy numbers. The most important three sub-factors are identified as education, product responsibility and work environment. Five different salary groups are determined depending on analysis. We made our conclusions in Section-5. Extensions of our approach and future work are also explained in Section-5.

\section{FUZZY ANALYTIC HIERARCHY PROCESS}

Analytic Hierarchy Process (AHP) is the initial MCDM method and it is appropriate for studying complicated multi criteria problems. Saaty (1980) introduced AHP and applied it to various MCDM problems from production [16-18] to energy [19-21], investment [22], location [23-24] and farming activities [25]. The structure of MCDM problems encountered in everyday life usually do not contain reviews can be expressed with definite numbers. Decision making processes always involve fuzziness and uncertainty due to the nature of comparison. There is a considerably high probability of drawing a wrong conclusion because of the linguistic assessments of DMs in the evaluation stages. Hence, MCDM methods should be modified to include the fuzziness in such cases [26].

Fuzzy set theory and hierarchical structure analysis combining fuzziness and AHP are employed in many studies in literature [27-34]. As a comprehensive MCDM technique, F-AHP has been usually employed for studying complicated problems. During any managerial evaluation it is more confident to make interval 
judgments than rigid ones, since it is difficult to determine preferences due to fuzziness of the comparisons. A methodical approach to selection and justification problem is F-AHP. F-AHP was employed for the evaluation of computer integrated manufacturing processes [17]. It was also used for budgeting and the selection of best facility locations [35, 36]. Kwong and Bai (2003) prioritized customer requirements in QFD by F-AHP [37]. A similar approach was applied to choose the most excellent software development policy [18]. In addition AHP was employed for the evaluation of operating system, best transportation company and facility layout design respectively [22, 37-40].

\subsection{Fuzzy Set Theory}

Fuzzy set theory was introduced to include the uncertainty in decision making [41]. Its major contribution is the potential of symbolizing fuzzy data, which allows arithmetical operators and encoding application. A group of items with a range of membership scores and characterized by a characteristic function is called fuzzy set. A membership value between 0 and 1 is assigned to each object by characteristic function.



Figure 1. A representation of fuzzy number, $\widetilde{M}$

If the symbol represents a fuzzy set, a tilde ' $\sim$ ' is located above. A triangular fuzzy number (TFN), $\widetilde{M}$ is simply denoted by $(1 / \mathrm{m}, \mathrm{m} / \mathrm{u})$ or $(1, \mathrm{~m}, \mathrm{u})$ parameters in Figure 1 . In order to describe a fuzzy event, $1, \mathrm{~m}$ and $u$ parameters respectively show the smallest, the most promising and the largest possible values. The TFN membership function in (1) can be defined as

$\mu(x / \tilde{M})=\left\{\begin{array}{cl}0, & x<l, \\ (x-l) /(m-l), & l \leq x \leq m \\ (u-x) /(u-m), & m \leq x \leq u \\ 0, & x>u\end{array}\right.$

Left and right membership degree in (2) is always denoted with a fuzzy number:

$\tilde{M}=\left(M^{l(y)}, M^{r(y)}\right)=(l+(m-l) y, u+(m-u) y), \quad y \in[0,1]$,

1(y) and $\mathrm{r}(\mathrm{y})$ indicates left and right sides. For fuzzy numbers lots of grading approaches have been presented. They may provide diverse results and nearly all methods, requiring difficult mathematical calculations, are tiresome in graphic manipulations. Fuzzy number algebraic operations are presented in [35]. 


\subsection{Extent Analysis Technique}

Extent analysis technique is preferred in this study since it is easier than other methods [29, 30]. The steps are as follows: Let $X=\left\{x_{1}, x_{2}, \ldots, x_{n}\right\}$ be an object set, and $U=\left\{u_{1}, u_{2}, \ldots, u_{m}\right\}$ be a goal set [29,30]. Extent analysis for each goal, $g_{i}$, is performed with respect to this technique. Extent analysis values for each object $(m)$ are achieved by:

$M_{g i}^{1}, M_{g i}^{2}, \ldots, M_{g i}^{m},(i=1,2, \ldots, n)$

where all the $M_{g i}^{j}(j=1,2, \ldots, m)$ are in (3) TFNs. The steps are presented below:

Step 1: In (4), the value of fuzzy synthetic extent to the $i^{\text {th }}$ object is identified as

$S_{i}=\sum_{j=1}^{m} M_{g i}^{j} \otimes\left[\sum_{i=1}^{n} \sum_{j=1}^{m} M_{g_{i}}^{j}\right]^{-1}$

To obtain $\sum_{j=1}^{m} M_{g i}^{j}$ in (5), perform addition process of $m$ extent analysis values for a matrix like

$$
\sum_{j=1}^{m} M_{g i}^{j}=\left(\sum_{j=1}^{m} l_{j}, \sum_{j=1}^{m} m_{j}, \sum_{j=1}^{m} u_{j}\right)
$$

to achieve $\left[\sum_{i=1}^{n} \sum_{j=1}^{m} M_{g_{i}}^{j}\right]^{-1}$, perform addition function of $M_{g i}^{j}(j=1,2, \ldots, m)$ values in (6), such that

$$
\sum_{i=1}^{n} \sum_{j=1}^{m} M_{g_{i}}^{j}=\left(\sum_{i=1}^{n} l_{i}, \sum_{i=1}^{n} m_{i}, \sum_{i=1}^{n} u_{i}\right)
$$

after that calculate the opposite of the vector in (6) as in (7)

$$
\left[\sum_{i=1}^{n} \sum_{j=1}^{m} M_{g_{i}}^{j}\right]^{-1}=\left(\frac{1}{\sum_{i=1}^{n} u_{i}}, \frac{1}{\sum_{i=1}^{n} m_{i}}, \frac{1}{\sum_{i=1}^{n} l_{i}}\right)
$$

Step 2: The scale of possibility of $M_{2}=\left(l_{2}, m_{2}, u_{2}\right) \geq M_{l}=\left(l_{1}, m_{1}, u_{l}\right)$ is identified in (8) as $\mathrm{V}\left(M_{2} \geq M_{1}\right)=\sup \left[\min \left(\mu_{M_{1}}(x), \mu_{M_{2}}(y)\right)\right]$

and is defined in (9) such that

$$
\mathrm{V}\left(M_{2} \geq M_{1}\right)=\mu_{M_{2}}(d)= \begin{cases}1, & \text { if } m_{2} \geq m_{1} \\ 0, & \text { if } l_{1} \geq u_{2} \\ \frac{l_{1}-u_{2}}{\left(m_{2}-u_{2}\right)-\left(m_{1}-l_{1}\right)} & \text { or else }\end{cases}
$$


where $d$ is the ordinate of the maximum junction point $D$ among $\mu_{M_{1}}$ and $\mu_{M_{2}}$ (Figure 2). The rates of $V\left(M_{1} \geq M_{2}\right)$ and $V\left(M_{2} \geq M_{1}\right)$ are to be compared $M_{l}$ and $M_{2}$.



Figure 2. Intersection between $M_{1}$ and $M_{2}$

Step 3: Possibility degree used for a convex fuzzy number which is bigger than $k$ convex fuzzy numbers $\mathrm{Mi}(i=1,2, \ldots, k)$ is expressed in (10) by

$V\left(M \geq M_{1}, M_{2}, \ldots, M_{k}\right)=V\left[\left(M \geq M_{1}\right)\right.$ and $\left(M \geq M_{2}\right)$ and $\left.\ldots\left(M \geq M_{k}\right)\right]$

$=\operatorname{minV}\left(M \geq M_{i}\right), \quad i=1,2, \ldots, k$.

In (11) suppose that

$d^{\prime}\left(A_{i}\right)=\min V\left(S_{i} \geq S_{k}\right)$.

For $k=1,2, \ldots, n ; k \neq i$. Next weight vector in (12) is

$W^{\prime}=\left(d^{\prime}\left(A_{1}\right), d^{\prime}\left(A_{2}\right), \ldots, d^{\prime}\left(A_{n}\right)\right)^{\mathrm{T}}$,

where $A_{i}(i=1,2, \ldots, n)$ are $n$ factors.

Step 4: Normalized weight vectors in (13) are gathered through normalization

$W^{\prime}=\left(d\left(A_{1}\right), d\left(A_{2}\right), \ldots, d\left(A_{n}\right)\right)^{\mathrm{T}}$,

$W$ is a crisp number.

\section{METHOD}

Fuzzy Analytical Hierarchy Process (AHP) was employed for job evaluation so that more accurate results could have been obtained in factor selection and scoring. The proposed F-AHP job evaluation model consists of the seven steps:

Step 1: Factors and sub-factors identification.

Step 2: Establishment of the AHP structure.

Step 3: Determination of the local weights.

The fuzzy scale that will be used in Chang's fuzzy AHP model is presented in Figure 3 and Table 1. 


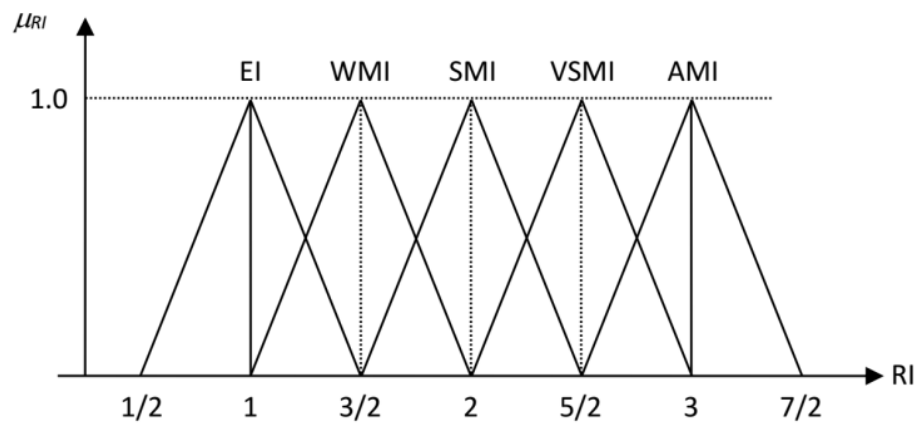

Figure 3. Linguistic scales

Table 1. Linguistic scales [19]

\begin{tabular}{|l|l|l|l|}
\hline Linguistic scale for difficulty & Linguistic scale for importance & Fuzzy Number & Reciprocal Number \\
\hline Just equal & Just equal & $(1,1,1)$ & $(1,1,1)$ \\
\hline Equally difficult (ED) & Equally important (EI) & $(1 / 2,1,3 / 2)$ & $(2 / 3,1,2)$ \\
\hline Weakly more difficult (WMD) & Weakly more important (WMI) & $(1,3 / 2,2)$ & $(1 / 2,2 / 3,1)$ \\
\hline Strongly more difficult (SMD) & Strongly more important (SMI) & $(3 / 2,2,5 / 2)$ & $(2 / 5,1 / 2,2 / 3)$ \\
\hline Very strongly more difficult (VSMD) & Very strongly more important (VSMI) & $(2,5 / 2,3)$ & $(1 / 3,2 / 5,1 / 2)$ \\
\hline Absolutely more difficult (AMD) & Absolutely more important (AMI) & $(5 / 2,3,7 / 2)$ & $(2 / 7,1 / 3,2 / 5)$ \\
\hline
\end{tabular}

Step 4: Overall weights calculation for sub-factors.

Step 5: The linguistic variables in Figure 4 proposed by [31] are employed to scale sub-factors.

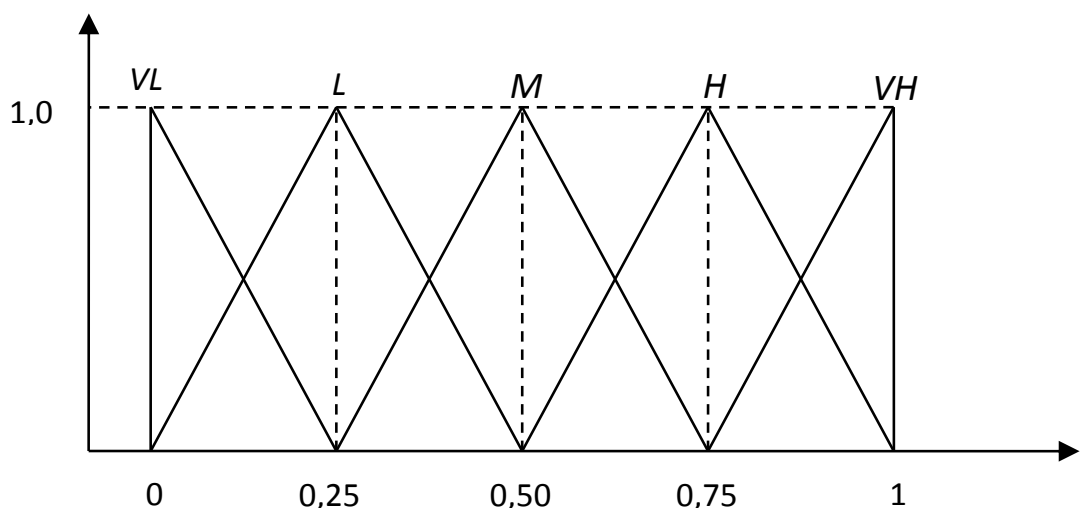

Figure 4. Membership functions

Step 6: The jobs are evaluated as explained at Step 4, 5 and total evaluation points are calculated accordingly.

Step 7: Determination of the wage groups.

The flowchart of the job evaluation process with fuzzy AHP is shown in Figure 5.

\section{RESULTS AND DISCUSSION}

In this section, professions in a metal factory, Ankara-Turkey are evaluated by F-AHP and results are presented. A decision committee was formed from three company managers in different departments. Authors of this paper were included in the team with the aim of explaining the F-AHP approach to decision committee members, but they were not participated in the evaluation and decision stage. 


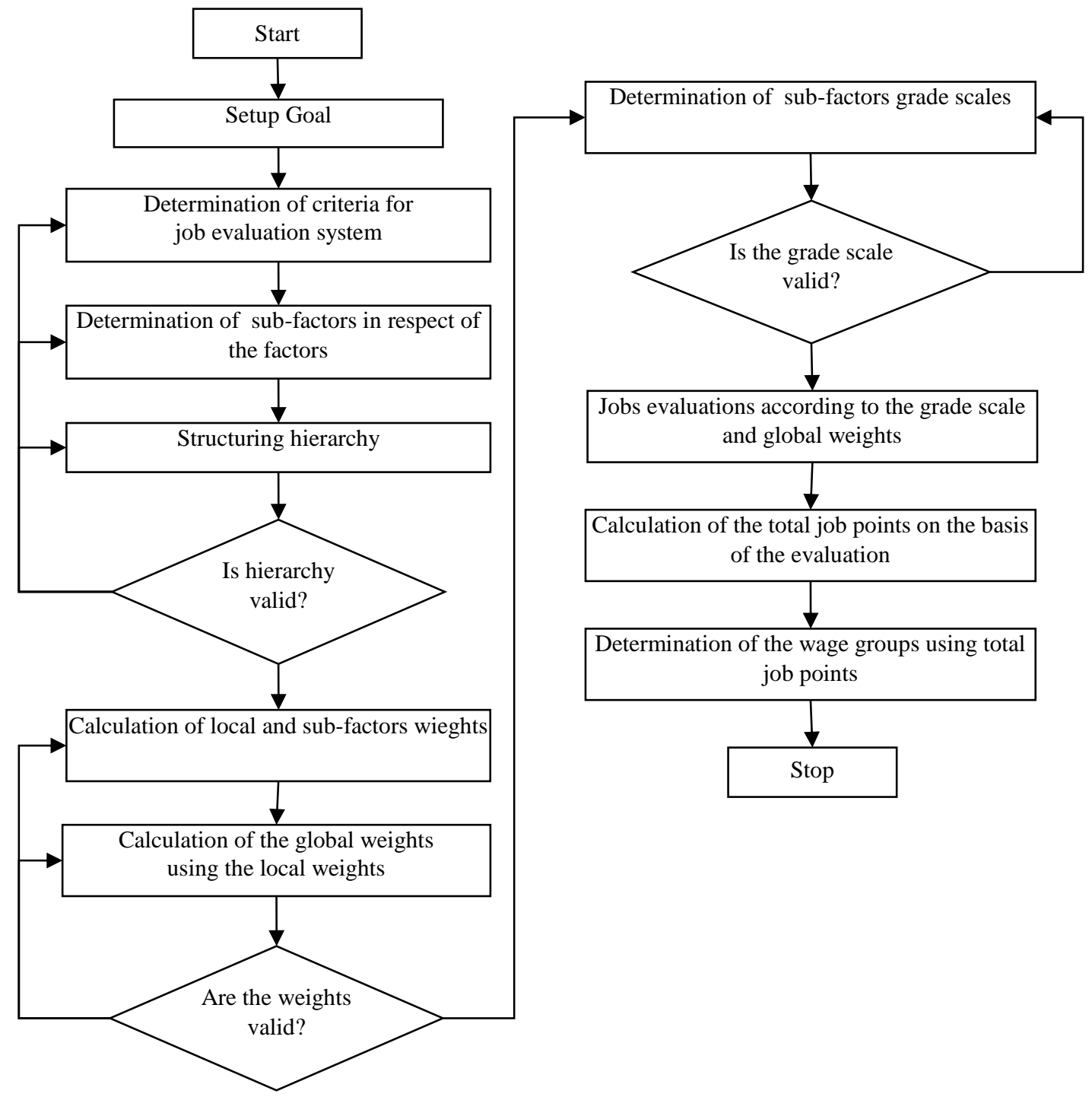

Figure 5. Job evaluation process with fuzzy AHP

Step 1: In this step, Turkish Trade Union of Metal Industry determined factors and sub-factors and these factors are employed in F-AHP applications. The 11 sub-factors are clustered under three factor groups; which are Mastery, Responsibility, and Effort Factors:

- Mastery Factors: Education, Experience, Skill, Initiative

- Responsibility Factors: Machine, Material, Product and Production responsibility

- Effort Factors: Mental effort, Physical effort, Work environment

The factors employed in this study were mainly based on the job evaluation criteria determined by Turkish Trade Union of Metal Industry [42]. The job evaluation factors and sub-factors determined by Turkish Trade Union of Metal Industry can be employed not only in metal industry but also in other industrial sectors. These types of factors were frequently used in job evaluations. The main contribution of this study is not the determination of these factors, but it is the development an analytical and objective job evaluation method. The factors and sub-factors are flexible, that new factors or sub factors can be included in evaluation process.

Step 2: Figure 6 illustrates 3 level hierarchy regarding factors and sub-factors. Objective is defined in the first level and factors and sub-factors are placed in other levels. 


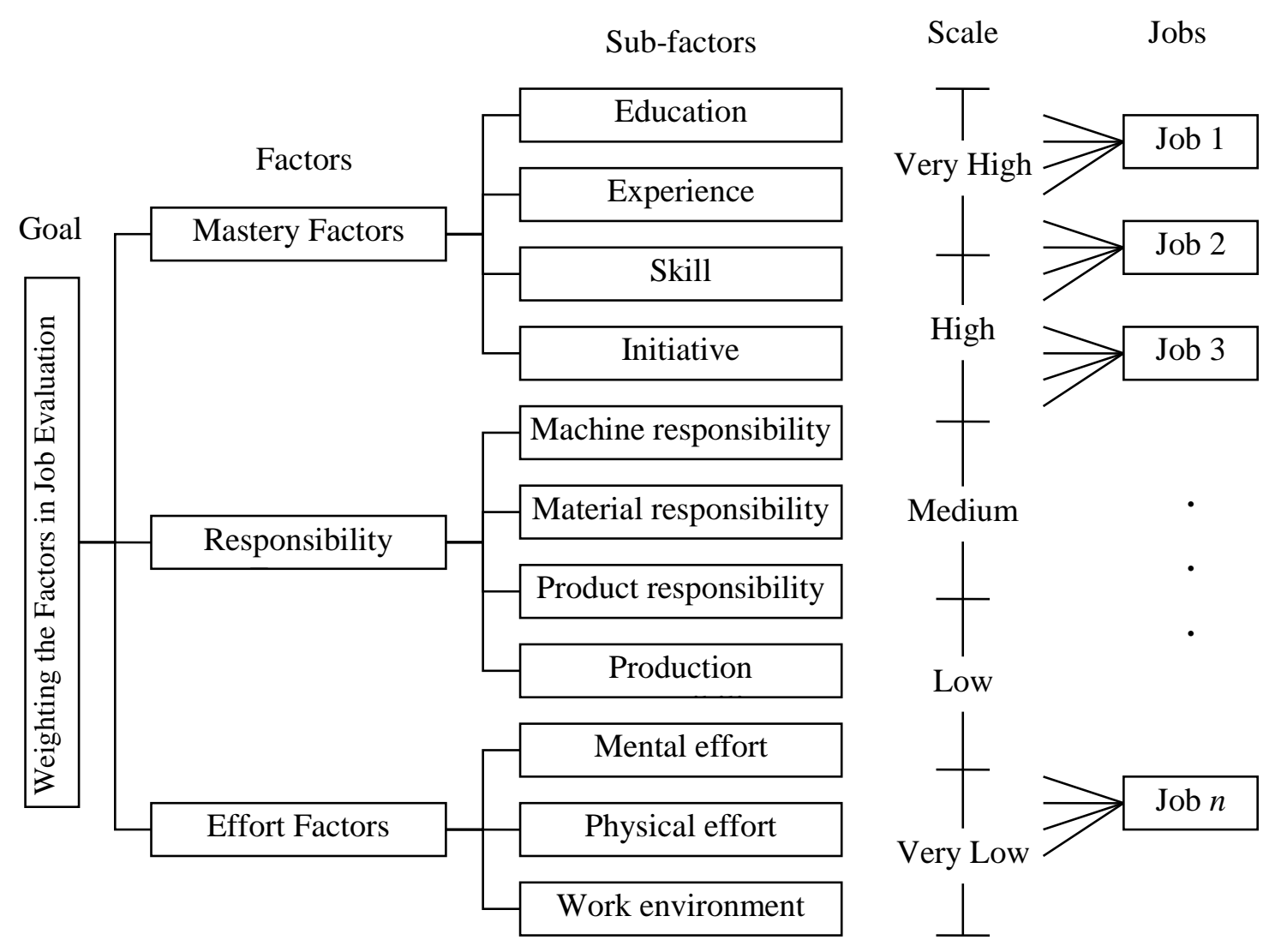

Figure 6. AHP Model

Step 3: Local factors and sub-factor weights are calculated with respect to pairwise comparisons. The decision committee evaluated all criteria pairwise without assuming any interdependence by using the Saaty's 1-9 scale and individual matrixes were formed. To obtain a general pairwise comparison matrix geometric means of individual comparison values are computed. These matrices are analyzed using extent analysis technique. Local factor weights are calculated (See Tables 2-4).

Table 2. Local weights and pairwise comparison matrix of main factors

\begin{tabular}{|l|l|l|l|l|}
\hline Main Factors & MF & RF & EF & Local Weights \\
\hline Mastery Factors (MF) & $(1,1,1)$ & $(3 / 2,2,5 / 2)$ & $(1 / 2,1,3 / 2)$ & 0.41 \\
\hline Responsibility Factors (RF) & $(2 / 5,1 / 2,2 / 3)$ & $(1,1,1)$ & $(3 / 2,2,5 / 2)$ & 0.35 \\
\hline Effort Factors (EF) & $(2 / 3,1,2)$ & $(2 / 5,1 / 2,2 / 3)$ & $(1,1,1)$ & 0.24 \\
\hline
\end{tabular}

Table 3. Local weights and pair wise comparison matrix of mastery sub-factors

\begin{tabular}{|l|l|l|l|l|l|}
\hline Mastery Factors & $\mathrm{Ed}$ & $\mathrm{Ex}$ & $\mathrm{S}$ & $\mathrm{I}$ & Local Weights \\
\hline Education (Ed) & $(1,1,1)$ & $(1,3 / 2,2)$ & $(1,3 / 2,2)$ & $(3 / 2,2,5 / 2)$ & 0.37 \\
\hline Experience (Ex) & $(1 / 2,2 / 3,1)$ & $(1,1,1)$ & $(1 / 2,1,3 / 2)$ & $(1,3 / 2,2)$ & 0.25 \\
\hline Skill $(\mathrm{S})$ & $(1 / 2,2 / 3,1)$ & $(2 / 3,1,2)$ & $(1,1,1)$ & $(1,3 / 2,2)$ & 0.26 \\
\hline Initiative (I) & $(2 / 5,1 / 2,2 / 3)$ & $(1 / 2,2 / 3,1)$ & $(1 / 2,2 / 3,1)$ & $(1,1,1)$ & 0.12 \\
\hline
\end{tabular}

Table 4. Local weights and pairwise comparison matrix of responsibility sub-factors

\begin{tabular}{|l|l|l|l|l|l|}
\hline Responsibility Factors & PR & MR & PrR & MtR & Local Weights \\
\hline Product Res. (PR) & $(1,1,1)$ & $(5 / 2,3,7 / 2)$ & $(2 / 7,1 / 3,2 / 5)$ & $(1,3 / 2,2)$ & 0.31 \\
\hline Machine Res. (MR) & $(2 / 7,1 / 3,2 / 5)$ & $(1,1,1)$ & $(3 / 2,2,5 / 2)$ & $(1,3 / 2,2)$ & 0.24 \\
\hline Production Res.(PrR) & $(5 / 2,3,7 / 2)$ & $(2 / 5,1 / 2,2 / 3)$ & $(1,1,1)$ & $(2 / 5,1 / 2,2 / 3)$ & 0.25 \\
\hline Material Res. (MtR) & $(1 / 2,2 / 3,1)$ & $(1 / 2,2 / 3,1)$ & $(3 / 2,2,5 / 2)$ & $(1,1,1)$ & 0.20 \\
\hline
\end{tabular}


Table 5. Local weights and pairwise comparison matrix of effort sub-factors

\begin{tabular}{|l|l|l|l|l|}
\hline Effort Factors & ME & PE & WE & Local Weights \\
\hline Mental effort (ME) & $(1,1,1)$ & $(1,3 / 2,2)$ & $(1 / 2,2 / 3,1)$ & 0.34 \\
\hline Physical effort (PE) & $(1 / 2,2 / 3,1)$ & $(1,1,1)$ & $(2 / 5,1 / 2,2 / 3)$ & 0.10 \\
\hline Work environment (WE) & $(1,3 / 2,2)$ & $(3 / 2,2,5 / 2)$ & $(1,1,1)$ & 0.56 \\
\hline
\end{tabular}

Step 4: Global weights are computed with respect to local weights of the factors and sub-factors and presented at Table 5. The global weights are normalized in order to make evaluations on a scale of 1000 points.

Table 6. Global sub-factor weights

\begin{tabular}{|l|l|l|l|l|}
\hline Main factors \& local weights & Sub Factors & $\begin{array}{l}\text { Local } \\
\text { Weights }\end{array}$ & $\begin{array}{l}\text { Global } \\
\text { Weights }\end{array}$ & $\begin{array}{l}\text { Normalized } \\
\text { Weights }\end{array}$ \\
\hline \multirow{5}{*}{ Mastery Factors (MF) } & Education (Ed) & 0.37 & 0.159 & 159 \\
\cline { 2 - 5 } & Experience (Ex) & 0.25 & 0.107 & 107 \\
\cline { 2 - 5 } & Skill (S) & 0.26 & 0.111 & 111 \\
\cline { 2 - 5 } & Initiative(I) & 0.12 & 0.052 & 52 \\
\hline Responsibility Factors (RF) & Product Responsibility (PR) & 0.31 & 0.115 & 115 \\
\cline { 2 - 5 } & Machine responsibility (MR) & 0.24 & 0.089 & 89 \\
\cline { 2 - 5 } & Production responsibility (PrR) & 0.25 & 0.093 & 93 \\
\cline { 2 - 5 } & Material responsibility (MtR) & 0.20 & 0.074 & 74 \\
\hline Effort Factors (EF) & Mental effort (ME) & 0.34 & 0.068 & 68 \\
\cline { 2 - 5 } & Physical effort (PE) & 0.10 & 0.020 & 20 \\
\cline { 2 - 5 } & Work environment (WE) & 0.56 & 0.112 & 112 \\
\hline
\end{tabular}

The most important three sub-factors for job evaluation in metal industry are identified as education, product responsibility, working environment (see Table 6).

Step 5-6: Global sub-factor weights (see Table 6) and the linguistic variables (see Table 1) are employed to evaluate two different jobs in Table 7.

Step 7: It is determined that the value of the first job is 580 and the second is 375 . The remaining jobs are evaluated similarly and the salary clusters are determined in accordance with job points illustrated in Figure 7. During this process, acceptable wage-scale law and the wage policies in similar companies are taken into account.

Table 7. Evaluation of two different jobs

\begin{tabular}{|c|c|c|c|c|c|c|c|}
\hline \multirow{2}{*}{$\begin{array}{l}\text { Sub } \\
\text { Factors }\end{array}$} & \multirow{2}{*}{$\begin{array}{c}\text { Global } \\
\text { weights }\end{array}$} & \multicolumn{3}{|c|}{ Job 1} & \multicolumn{3}{|c|}{ Job 2} \\
\hline & & Scale & Scale Value & Point & Scale & Scale Value & Point \\
\hline Education $(\mathrm{Ed})$ & 159 & $\mathrm{M}$ & 0.5 & 79.5 & $\mathrm{~L}$ & 0.25 & 39.7 \\
\hline Experience (Ex) & 107 & $\mathrm{H}$ & 0.75 & 80.2 & $\mathrm{~L}$ & 0.25 & 26.7 \\
\hline Skill (S) & 111 & $\mathrm{H}$ & 0.75 & 83.2 & $\mathrm{~L}$ & 0.25 & 27.7 \\
\hline Initiative(I) & 52 & $\mathrm{M}$ & 0.5 & 26.0 & VL & 0 & 0 \\
\hline Product Responsibility (PR) & 115 & $\mathrm{~L}$ & 0.25 & 28.7 & $\mathrm{M}$ & 0.5 & 57.5 \\
\hline Machine responsibility (MR) & 89 & $\mathrm{H}$ & 0.75 & 66.7 & $\mathrm{H}$ & 0.75 & 66.7 \\
\hline Production responsibility (PrR) & 93 & $\mathrm{H}$ & 0.75 & 69.7 & $\mathrm{M}$ & 0.5 & 46.5 \\
\hline Material responsibility (MtR) & 74 & $\mathrm{VH}$ & 1 & 74 & $\mathrm{H}$ & 0.75 & 55.5 \\
\hline Mental effort (ME) & 68 & $\mathrm{M}$ & 0.5 & 34 & $\mathrm{~L}$ & 0.25 & 17 \\
\hline Physical effort (PE) & 20 & $\mathrm{M}$ & 0.5 & 10 & $\mathrm{M}$ & 0.5 & 10 \\
\hline Working environment (WE) & 112 & $\mathrm{~L}$ & 0.25 & 28 & $\mathrm{~L}$ & 0.25 & 28 \\
\hline & & & \begin{tabular}{|l|l} 
Job 1 \\
\end{tabular} & 580 & & Job 2 & 375 \\
\hline
\end{tabular}




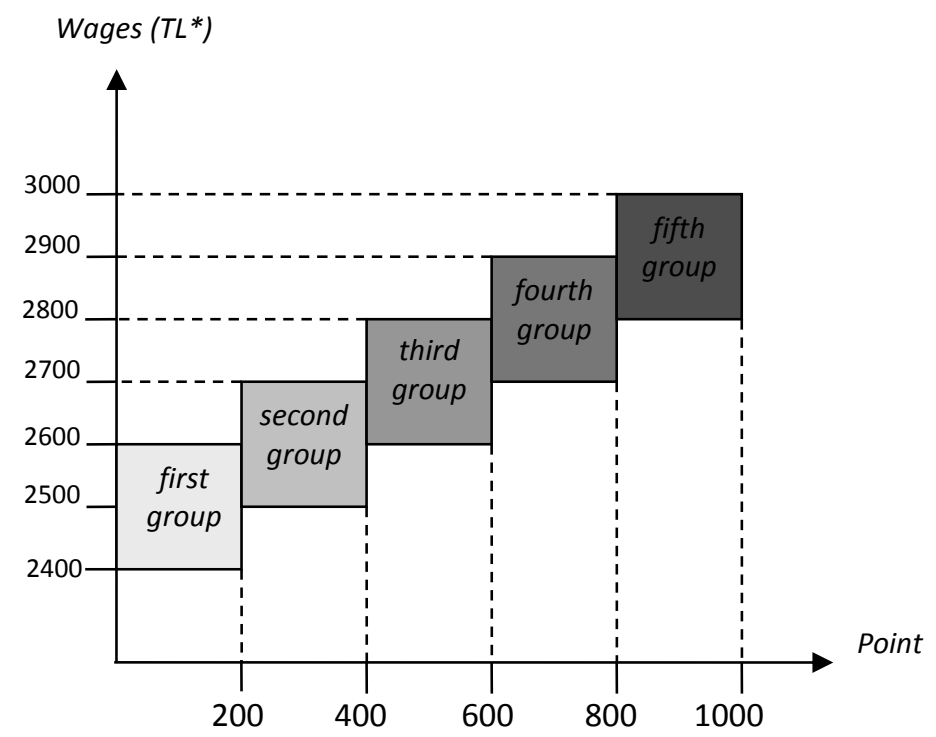

Figure 7. The wage groups determined on the basis of total points (*TL:Turkish Lira)

The payment structure with five different wage groups within an interval of 2400 -3000 TL (Turkish Lira) is established with respect to job points. The salary of a worker in the first wage group could be higher than the second group with respect to his/her experience and status in the company. Using the job points in Table 7, job1 is included in the third group and the job2 is in second group. In this manner, a reliable payment system is created.

The functional independence of an upper part of the hierarchy from all its lower parts is the fundamental assumption of AHP. Because they include the interaction and dependence of higher level elements on lower levels, a lot of MCDM problems cannot be arranged hierarchically [43, 44]. AHP was suggested to study the problem of independence and ANP was suggested to study the problem of dependence between alternatives or criteria [45].

The ANP is a generalization of AHP [44]. Whereas AHP represents a framework with a unidirectional hierarchical relationship, ANP allows for complex interrelationships among decision levels [46]. There are many studies in the literature using ANP [47-51]. In order to establish a rational pay structure, job evaluation makes systematic comparisons between jobs to assess their relative worth. It is a systematic way of determining the worth of a job in relation to other jobs [52]. A data-driven model for job categorization and evaluation is presented by [53]. Multi Criteria Decision Making tools e.g. AHP [54] fuzzy TOPSIS [55-57], fuzzy ELECTRE [58], AHP-PROMETHEE [59] AHP-TOPSIS [60], ELECTRE-AHP [61] are employed not only in job evaluation but also in job analysis, staff selection and job satisfaction analysis to create a more efficient working environment [62-64]. The MCDM methods were combined with each other or fuzzy logic during job evaluation or analysis [59-61, 65-70].

\section{CONCLUSION}

In organizations, most of the decisions depend on the subjective assessments of managers though many conflicting factors and alternatives are compared and as a result decision making includes fuzzy factors. Thus fuzzy decision making theory may be easily employed to evaluate complex environments. On the whole, different MCDM techniques should be employed to make more accurate decisions.

In job evaluation, the available information for DMs is unclear and doubtful. Obtaining precise assessment data (for example while describing jobs) is not easy. The evaluation problem is considered as a MCDM problem under fuzzy environment and structure of problem was analyzed by F-AHP. The vagueness and subjectivity of DM's judgments are overcome with linguistic values. F-AHP and triangular fuzzy numbers are employed for determining weights. 
This study reveals the advantages of F-AHP in differentiating various jobs, where F-AHP provides satisfactory results for a reliable payment system. The applicability and effectiveness of F-AHP evaluation method on classical job evaluation approaches has been demonstrated. Although F-AHP job evaluation method was applied in a specific company, the method is useful and analytically easy to apply for other sectors. An extension to this study may consider the factors and sub-factors relationships between by Analytical Network Process (ANP). Another extension may be converting the fuzzy scale from triangular to trapezoidal numbers. Both extensions may help obtaining more accurate results in job evaluation.

\section{CONFLICTS OF INTEREST}

No conflict of interest was declared by the authors.

\section{REFERENCES}

[1] Spyridakos, A., Siskos, Y., Yannacopoulos, D., Skouris, A., "Multicriteria job evaluation for large organizations", European Journal of Operational Research, 130: 375-387, (2001).

[2] Arthurs, A.J., "Job design and evaluation: organizational aspects", International Encyclopedia of the Social \& Behavioral Sciences (Second Edition), 816-818, (2015).

[3] McCormick, E.M., “Job analysis: methods and application”, New York, (1979).

[4] Doverspike, D., Carlisi, A.M., Garrett, G.V., Alexander, R.A., "Generalizability analysis of a pointmethod job evaluation instrument", Journal of Applied Psychology, 68: 476-483, (1983).

[5] Das,B., Garcia-Diaz, A., "Factor selection guidelines for job evaluation: a computerized statistical procedure", Computers \& Industrial Engineering, 40: 259-272, (2001).

[6] Rutt, S.M., Doverspike, D., "Salary and organizational level effects on job evaluation ratings", Journal of Business and Psychology, 14: 379-385, (1999).

[7] Figart, D.M., "Equal pay for equal work: the role of job evaluation in an evolving social norm", Journal of Economic Issues, 34: 1-19, (2000).

[8] Smith, B.N., Benson, P.G., Hornsby, J.S., "The effects of job description content on job evaluation judgments”, Journal of Applied Psychology, 75: 301-309, (1990).

[9] Weiner, N.J., "Job evaluation systems: a critique", Human Resource Management Review, 1: 119$132,(1991)$.

[10] Tiffany, C., Lütjens, L.R., "Pay inequity: it's still with us", Journal of Professional Nursing, 9: 50-55, (1993).

[11] Mahmood, M.A., Gowan, M.A., Wang, S., "Developing a prototype job evaluation expert system: a compensation management application", Information \& Management, 29: 9-28, (1995).

[12] Gupta, J.N.D., Ahmed, N.U., "A goal programming approach to job evaluation", Computers \& Industrial Engineering, 14: 147-152, (1988).

[13] Dağdeviren, M., Kurt, M., "Job evaluation, use of goal programming technique at determine factor degree points", Journal of the Faculty of Engineering and Architecture of Gazi University, 19: 89-95, (2004). 
[14] Gupta, S., Chakraborty, M., "Job evaluation in fuzzy environment”, Fuzzy Sets and Systems, 100: 7176, (1988).

[15] Saaty, T.L., "The analytic hierarchy process", McGraw-Hill, New York, (1980).

[16] Dağdeviren, M, Eren, T., "Analytic hierarchy process and use of 0-1 goal programming methods in selecting supplier firm", Journal of the Faculty of Engineering and Architecture of Gazi University, 16: 41-52, (2001).

[17] Bozdağ, C.E., Kahraman, C., Ruan, D., "Fuzzy group decision making for selection among computer integrated manufacturing systems", Computers in Industry, 51:13-29, (2003).

[18] Büyüközkan, G., Ertay, T., Kahraman, C., Ruan, D., "Determining the importance weights for the design requirements in the house of quality using the fuzzy analytic network approach", International Journal of Intelligent Systems, 19: 443-461, (2004).

[19] Xiaohua, W., Zhenmin, F., "Sustainable development of rural energy and its appraising system in Chine", Renewable \& Sustainable Energy Reviews, 6: 395-404, (2002).

[20] Yedla, S., Shresta, R.M., "Multi-criteria approach for the selection of alternative options for environmentally sustainable transport system in Delhi", Transportation Research, 37: 717-729, (2003).

[21] Aras, H., Erdogmus, S., Koc, E., "Multi-criteria selection for a wind observation station location using analytic hierarchy process", Renewable \& Sustainable Energy Reviews, 29:1383-1392, (2004).

[22] Tolga,E., Demircan, M.L., Kahraman, C., "Operating system selection using fuzzy replacement analysis and analytic hierarchy process", International Journal of Production Economics, 97: 89-117, (2005).

[23] Kim P.P, Lee K.J, Lee B.W., "Selection of an optimal nuclear fuel cycle scenario by goal programming and the analytic hierarchy process", Annals of Nuclear Energy, 26: 449-460 (1999).

[24] Kuo R.J., Chi S.C., Kao, S.S., “A decision support system for selection convenience store location through integration of fuzzy AHP and artificial neural network", Computers in Industry, 47: 199-214, (2002).

[25] Wolfslehner, B., Vacik, H., Lexer, M.J., "Application of the analytic network process in multi-criteria analysis of sustainable forest management", Forest Ecology and Management, 207: 157-170, (2005).

[26] Yılmaz, B., Dağdeviren, M., "Comparative analysis of PROMETHEE and fuzzy PROMETHEE methods in equipment selection problem", Journal of the Faculty of Engineering and Architecture of Gazi University, 25(4): 811-826, (2010).

[27] Van Laarhoven, P.J.M, Pedrycz, W., “A fuzzy extension of Saaty’s priority theory”, Fuzzy Sets and Systems, 11: 229-241, (1983).

[28] Buckley, J.J., “Fuzzy hierarchical analysis”, Fuzzy Sets and Systems, 17: 233-247 (1985).

[29] Chang, D.Y., "Extent analysis and synthetic decision, optimization techniques and applications", World Scientific, Singapore, (1992).

[30] Chang, D.Y., "Applications of the extent analysis method on fuzzy AHP", European Journal of Operational Research, 95: 649-655, (1996). 
[31] Cheng, C.H., "Evaluating naval tactical missile systems by fuzzy AHP based on the grade value of membership function", European Journal of Operational Research, 96: 343-350, (1997).

[32] Deng, H., "Multi-criteria analysis with fuzzy pairwise comparison", International Journal of Approximate Reasoning, 21: 215-231, (1999).

[33] Leung, L.C., Cao, D., “On consistency and ranking of alternatives in fuzzy AHP”, European Journal of Operational Research, 124: 102-113, (2000).

[34] Mikhailov, L., "A fuzzy approach to deriving priorities from interval pairwise comparison judgments", European Journal of Operational Research, 159: 687-704, (2004).

[35] Kahraman, C., Ruan, D., Tolga, E., "Capital budgeting techniques using discounted fuzzy versus probabilistic cash flows", Information Sciences, 42: 57-76, (2002).

[36] Kahraman, C., Ruan, D., Doğan, İ., "Fuzzy group decision-making for facility location selection", Information Sciences, 157: 135-153, (2003).

[37] Kwong, C.K., Bai, H., "Determining the importance weights for the customer requirements in QFD using a fuzzy AHP with an extent analysis approach”, IIE Transactions, 35: 619-626, (2003).

[38] Kulak, O., Kahraman, C., "Fuzzy multi-attribute selection among transportation companies using axiomatic design and analytic hierarchy process", Information Sciences, 170: 191-210, (2005).

[39] Erensal, Y.C., Öncan, T., Demircan, M.L., "Determining key capabilities in technology management using fuzzy analytic hierarchy process: a case study of Turkey", Information Sciences, 176: 27552770, (2006).

[40] Ertay, T., Ruan, D., Tuzkaya, U.R. "Integrating data envelopment analysis and analytic hierarchy for the facility layout design in manufacturing systems", Information Sciences, 176: 237-262, (2006).

[41] Zadeh, L.A., "Fuzzy sets", Information and Control, 8: 338-353, (1965).

[42] Turkish Metal Industry, "Metal industry work grouping system", Turkish Metal Industry Union Publications, Ankara, (1996).

[43] Saaty, T.L., Takizawa, M., "Dependence and independence: from linear hierarchies to nonlinear networks", European Journal of Operational Research, 26: 229-237, (1986).

[44] Saaty, T.L., "Decision making with dependence and feedback: the analytic network process", RWS Publications, Pittsburgh, (1996).

[45] Yüksel, İ., Dağdeviren, M., "Using the analytic network process (ANP) in a SWOT analysis - a case study for a textile firm", Information Sciences, 177: 3364-3382, (2007).

[46] Meade, L.M., Sarkis, J., "Analyzing organizational project alternatives for agile manufacturing processes: an analytical network approach", International Journal of Production Research, 37: 241261, (1999).

[47] Ayağ, Z., Özdemir, R.G., "A hybrid approach to concept selection through fuzzy analytic network process", Computers \& Industrial Engineering, 56: 368-379, (2009).

[48] Lee, H., Lee, S., Park, Y., "Selection of technology acquisition mode using the analytic network process", Mathematical and Computer Modeling, 49: 1274-1282, (2009). 
[49] Boran, S., Göztepe, K., "Development of a fuzzy decision support system for commodity acquisition using fuzzy analytic network process", Expert Systems with Applications, 37: 1939-1945, (2010).

[50] Vinodh, S., Ramiya, R.A., Gautham, S.G., "Application of fuzzy analytic network process for supplier selection in a manufacturing organization”, Expert Systems with Applications, 38: 272-280, (2011).

[51] Şenol, M.B., Dağdeviren, M., Kurt, M., "A multi criteria approach for aircraft cockpit interface evaluation", Journal of the Faculty of Engineering and Architecture of Gazi University, 28 (4): 685693, (2013).

[52] Arthurs, A.J., "Job design and evaluation: organizational aspects", International Encyclopedia of the Social \& Behavioral Sciences, 2: 816-818, (2015).

[53] Imhoff, R., Koch, A., Flade, F., "Preoccupations: a data-driven model of jobs and its consequences for categorization and evaluation", Journal of Experimental Social Psychology, 77: 76-88, (2018).

[54] Koutra, G., Kardaras, D., Barbounaki, S., Stalidis G.A., "Multi criteria model for personnel selection in maritime industry in Greece", IEEE 19th Conference on Business Informatics (CBI), Thessaloniki, 287-294, (2017).

[55] Sang, X., Liu, X., Qin, J., “An analytical solution to fuzzy TOPSIS and its application in personnel selection for knowledge-intensive enterprise”, Applied Soft Computing, 30: 190-204, (2015).

[56] Değirmenci, A., Ayvaz, B., "Fuzzy environment multi criteria decision making techniques personnel selection: participation in an application in banking sector", Istanbul Commerce University Journal of Science, 15(30): 77-93, (2016).

[57] Efe, B., Kurt, M., “A systematic approach for an application of personnel selection in assembly line balancing problem", International Transactions in Operational Research, 25: 1001-1025, (2018).

[58] Rouyendegh, B.D., Erkan, T.E., "An application of the Fuzzy ELECTRE method for academic staff selection", Human Factors and Ergonomics in Manufacturing \& Service Industries, 23(2): 107-115, (2013).

[59] Bedir, N., Eren, T., "AHP - PROMETHEE method with integration of personnel selection problem: a case study for the retail sector", Social Sciences Research Journal, 4(4): 46-58, (2015).

[60] Doğan, A., Önder, E., "Using multi criteria decision techniques in recruiting and selection of human resources and an application", Journal of Yasar University, 9(34): 5796-5819, (2014).

[61] Mojaheed, M., Marjani., M.E., Afshari, A.R., Marjani, S., "Using ELECTREAHP as a mixed method for personnel selection", Proceedings of the Symposium on the Analytic Hierarchy Process, Kuala Lumpur, Malaysia, (2013).

[62] Sabuncuoğlu, Z., “İnsan kaynakları yönetimi”, Aktuel Yayınları, Bursa, (2016).

[63] Çelikbilek, Y., "A grey analytic hierarchy process approach to project manager selection", Journal of Organizational Change Management, 31 (3): 749-765, (2017).

[64] Eyupoglu, Ş.Z., Jabbarov, K., Saner, T., "Job satisfaction: an evaluation using a fuzzy approach. Procedia Computer Science, 120: 691-698, (2017). 
[65] Köse, E., Aplak, H.S., Kabak, M., "An integrated approach based on grey system theory for personnel selection”, EGE Academic Review, 13(4): 461-471, (2013).

[66] Bali, Ö., "A MADM model by fuzzy extent analysis and fuzzy VIKOR: personnel selection problem", KHO Bilim Dergisi, 23(2): 125149, (2013).

[67] Özbek, A., "Selecting the managers through the method of multi criteria decision making", Journal of Management and Economics Research, 24: 209-225, (2014).

[68] Akbaş, S., Dalkılıç, T.E., "Multi criteria supplier selection based on fuzz comparison in AHP", Gazi University Journal of Science, 31(1): 296-308, (2018).

[69] Özyürek, İ., Mürsel, E., "Assessment of qualification criteria described in public procurement law code 4734 in construction works by analytic hierarchy process", Gazi University Journal of Science, 31(2): 437-454, (2018).

[70] Orman, A., Düzkaya, H., Ulvi, H., Akdemir, F., "Multi criteria evaluation by means of analytic hierarchy process in transportation master plans: scenario selection in the transportation master plan of Ankara", Gazi University Journal of Science, 31(2): 381-397, (2018). 